\title{
THE PRODUCTION OF LOLINE ALKALOIDS IN ARTIFICIAL AND NATURAL GRASS/ENDOPHYTE ASSOCIATIONS
}

\author{
O.J.-P. BALL and B.A. TAPPER \\ AgResearch, Grasslands Research Centre, \\ Private Bag 11008, Palmerston North
}

\begin{abstract}
Infection of grasses by Neotyphodium spp. endophytes is associated with the presence of alkaloids. This study investigated the production of loline alkaloids in endophyte-infected tall fescue, meadow fescue and perennial ryegrass. Most of the grass/endophyte associations were artificially created by inoculating parent plants with different Neotyphodium endophytes. The presence of lolines was dependent upon endophyte species and strain, but host species also influenced which lolines were produced. Concentrations of the different lolines, and the ratio at which they occurred, were also dependent upon endophyte isolate and host species. These findings are significant given that lolines contribute to host resistance against some insect pests.
\end{abstract}

Keywords: endophyte, Neotyphodium, lolines, fescue, ryegrass.

\section{INTRODUCTION}

Infection of pasture grasses such as perennial ryegrass (Lolium perenne) and tall fescue (Festuca arundinacea) with fungal endophytes belonging to the genus Neotyphodium, confers resistance to the host against a number of insect pests (Popay and Rowan 1994). However, their presence is also associated with a number of health problems in grazing livestock including ryegrass staggers and fescue toxicosis (Fletcher and Easton 1997). Research has indicated that insect resistance and livestock health effects are caused by the presence of alkaloids in infected plants (Dahlman et al. 1991; Fletcher and Easton 1997). In perennial ryegrass infected with N. lolii and tall fescue infected with $N$. coenophialum, the two most intensively studied grass/ endophyte systems, research has focussed on four alkaloids, or alkaloid groups. These are peramine, ergovaline, lolitrem B and the lolines. Typically, peramine, ergovaline and lolitrem B are associated with $N$. lolii infection of perennial ryegrass. Peramine, ergovaline and lolines occur in $N$. coenophialum-infected tall fescue. The loline alkaloids are the focus of the present paper.

The lolines associated with infection of grasses by someNeotyphodium endophytes are saturated pyrrolizidine alkaloids. Their role in mammalian toxicity is uncertain (Bush et al. 1993) and requires further investigation. However, some insects are adversely affected by their presence (Dahlman et al. 1991). In tall fescue infected with $N$. coenophialum and meadow fescue (Festuca pratensis) infected with $N$. uncinatum, $N$-formyl loline (NFL) and $N$-acetyl loline (NAL) are the major lolines produced, with NFL the dominant component (Yates et al. 1990; Justus et al. 1997). Another loline often present in endophyte-infected tall fescue and meadow fescue is $\mathrm{N}$-acetyl norloline (NANL).

In New Zealand, endophyte research has focused on the development of grasses that contain the insect resistance factors (e.g. peramine), but not the mammalian toxins (e.g. lolitrem B and ergovaline). This has been accomplished by identifying naturally occurring endophyte isolates which produce the desired range of alkaloids, and artificially inoculating them into commercial grass lines (Latch and Christensen 1985). Lolines have received little attention in New Zealand as they are absent from 
perennial ryegrass infected with $N$. lolii. While more information on the effects of lolines on New Zealand insect pests and their impact on livestock performance in general is required, the known insect resistance properties of lolines suggest that their presence could be useful. Thus, an understanding of the production of lolines, particularly in artificial grass/endophyte associations producing atypical alkaloid profiles, may be important. This paper therefore examines the effects of host species and endophyte isolate on the production of the loline alkaloids NFL, NAL and NANL.

\section{Grass plants}

\section{METHODS}

Tall fescue, meadow fescue and perennial ryegrass plants were used. Most infected plants were grown from seed of parent plants artificially inoculated with selected Neotyphodium endophytes (Latch and Christensen 1985). Many of the inoculated endophytes originated from tall fescue plants collected from southern Europe and northern Africa. Although the endophyte of tall fescue has usually been identified simply as $N$. coenophialum, three distinct taxonomic groupings of Neotyphodium endophytes from tall fescue have been described, only one of which fits the description of $N$. coenophialum (Christensen et al. 1993). Endophytes from all three taxonomic groupings were included in the study (Tables 1-3). The majority of artificial grass/endophyte associations used in the study expressed atypical alkaloid profiles. However, meadow fescue, tall fescue and perennial ryegrass naturally infected, respectively, with $N$. uncinatum, $N$. coenophialum and $N$. lolii strains producing typical alkaloid spectra, were also included. Plants were grown in potting mix and maintained outdoors in earthenware pots at the Department of Entomology and Plant Pathology, University of Tennessee, Knoxville, Tennessee, USA. Fertiliser and water were applied as required and plants were trimmed regularly to a height of $150 \mathrm{~mm}$.

\section{Harvest of plant material}

Herbage samples, consisting of pseudostem and lower leaf blade from vegetative tillers, were taken (from ground level to $150 \mathrm{~mm}$ ) from all plants in July 1996. These were frozen, freeze-dried, ground and stored at $-20^{\circ} \mathrm{C}$ until analysis for loline alkaloid content.

\section{Loline analysis}

Lolines were analysed by capillary gas chromatography (GC) using a modification of the method of Yates et al. (1990). Grass samples (100mg) were extracted for 60 minutes in $1 \mathrm{ml}$ of dichloroethane together with $50 \mu \mathrm{l}$ of methanol-water-ammonia solution (40\% methanol by volume, $5 \%$ ammonia by weight). After filtration, the resulting extracts were analysed for loline content by GC. NFL, NAL and NANL, the three major loline alkaloids associated with endophyte infection of tall fescue and meadow fescue were identified. The estimates of precision and limit of detection were $\pm 5 \%$ and $10 \mu \mathrm{g} / \mathrm{g}$ respectively. No standard for NANL was available, so concentrations of this alkaloid in herbage were calculated using NAL as the standard. Values for NANL were therefore only semi-quantitative.

\section{RESULTS}

Qualitative and quantitative differences in the production of the loline alkaloids were observed in tall fescue plants infected with different Neotyphodium spp. endophytes (Table 1). No lolines were found in tall fescue infected with AR508, and NFL and NAL were absent in associations containing AR542. Relative to other tall fescues in this study, high loline concentrations were recorded in some associations (wild type, AR513) and low concentrations in others (AR501, AR506). NFL concentrations were at least twice as high as NAL levels in tall fescue associations containing AR501, AR506 and the wild type endophyte. In tall fescue infected with AR512, AR513, AR514, AR524 and AR525, NFL and NAL concentrations were similar. Where all three lolines were present, NANL was always present in the lowest quantity. 
TABLE 1: Concentrations ( $\mu \mathrm{g} / \mathrm{g})$ of $N$-formyl loline (NFL), $N$-acetyl loline (NAL) and $N$-acetyl norloline (NANL) in tall fescue ${ }^{1}$ plants infected with different Neotyphodium endophytes ${ }^{2}$ (standard errors in brackets).

\begin{tabular}{llccccc}
\hline Endophyte & Taxon $^{3}$ & Type $^{4}$ & $\mathrm{n}^{5}$ & NFL & NAL & NANL $^{6}$ \\
\hline Wild type & N. coenophialum & $\mathrm{N}$ & 5 & $1043(236)$ & $351(81)$ & $91(62)$ \\
AR501 & FaTG-3 & A & 7 & $177(33)$ & $68(16)$ & $0(0)$ \\
AR506 & FaTG-3 & A & 6 & $265(65)$ & $84(23)$ & $0(0)$ \\
AR508 & Neotyphodium sp. & A & 3 & $0(0)$ & $0(0)$ & $0(0)$ \\
AR512 & N. coenophialum & A & 4 & $484(94)$ & $409(117)$ & $28(12)$ \\
AR513 & N. coenophialum & A & 4 & $929(103)$ & $969(122)$ & $88(14)$ \\
AR514 & N. coenophialum & A & 5 & $469(157)$ & $365(113)$ & Trace \\
AR524 & N. coenophialum & A & 4 & $269(168)$ & $288(190)$ & $227(137)$ \\
AR525 & N. coenophialum & A & 5 & $290(92)$ & $298(72)$ & $24(12)$ \\
AR542 & N. coenophialum & A & 5 & $0(0)$ & $0(0)$ & $260(47)$ \\
\hline
\end{tabular}

${ }^{1}$ All tall fescue plants were cv. 'Kentucky 31 '.

${ }^{2}$ All endophytes originated from tall fescue.

${ }^{3}$ Christensen et al. (1993). FaTG-3 = Festuca arundinacea taxonomic grouping 3.

${ }^{4}$ Type of association. $\mathrm{N}=$ natural, $\mathrm{A}=$ artificial.

${ }^{5}$ Number of replicate plants analysed.

${ }^{6}$ NANL concentrations calculated using NAL as the standard.

Loline alkaloids were not recorded in meadow fescue associations containing AR29, AR555 and AR583 (Table 2). There were large differences in the loline alkaloid content with the different endophytes. High concentrations of all three lolines were found in meadow fescue plants infected with AR548, while comparatively low levels were recorded in AR512-infected plants. In all loline-containing meadow fescue associations, concentrations of NFL were at least double those of NAL. Concentrations of NANL were consistently lower than NFL and NAL concentrations.

TABLE 2: Concentrations ( $\mu \mathrm{g} / \mathrm{g})$ of $N$-formyl loline (NFL), $N$-acetyl loline (NAL) and $N$-acetyl norloline (NANL) in meadow fescue ${ }^{1}$ plants infected with different Neotyphodium endophytes (standard errors in brackets).

\begin{tabular}{|c|c|c|c|c|c|c|c|}
\hline Endophyte & Taxon $^{2}$ & Host $^{3}$ & Type & $\mathrm{n}$ & NFL & NAL & NANL \\
\hline Wild type & N. uncinatum & MF & $\mathrm{N}$ & 6 & $909(225)$ & $329(63)$ & $284(66)$ \\
\hline AR29 & N. lolii & PRG & A & 4 & $0(0)$ & $0(0)$ & $0(0)$ \\
\hline AR501 & FaTG-3 & $\mathrm{TF}$ & A & 6 & $1501(412)$ & 446 (118) & 38 (14) \\
\hline AR506 & FaTG-3 & $\mathrm{TF}$ & A & 6 & $1618(335)$ & $434(84)$ & $43(12)$ \\
\hline AR512 & N. coenophialum & $\mathrm{TF}$ & A & 6 & $863(47)$ & $288(8)$ & $61(5)$ \\
\hline AR548 & N. coenophialum & $\mathrm{TF}$ & A & 5 & $2676(617)$ & $548(131)$ & $546(112)$ \\
\hline AR555 & FaTG-2 & TF & A & 6 & $0(0)$ & $0(0)$ & $0(0)$ \\
\hline AR565 & N. coenophialum & $\mathrm{TF}$ & A & 2 & $1991(843)$ & $581(110)$ & $113(28)$ \\
\hline AR583 & FaTG-2 & $\mathrm{TF}$ & A & 6 & $0(0)$ & $0(0)$ & $0(0)$ \\
\hline
\end{tabular}

${ }^{1}$ Meadow fescue infected with wild type endophyte was cv. 'Predix'; all other plants were cv. 'Ensign'.

${ }^{2}$ Christensen et al. (1993). FaTG-2 = Festuca arundinacea taxonomic grouping 2, FaTG-3 = Festuca arundinacea taxonomic grouping 3.

${ }^{3}$ Host species from which endophyte originated. $\mathrm{MF}=$ meadow fescue, $\mathrm{PRG}=$ perennial ryegrass, $\mathrm{TF}=$ tall fescue . 
No lolines were detected in perennial ryegrass plants naturally infected with the wild type endophyte (Table 3). Ryegrass infected with AR501 contained very low levels of NFL, but no NAL or NANL.

TABLE 3: Concentrations ( $\mu \mathrm{g} / \mathrm{g})$ of $N$-formyl loline (NFL), $N$-acetyl loline (NAL) and $N$-acetyl norloline (NANL) in perennial ryegrass ${ }^{1}$ plants infected with different Neotyphodium endophytes (standard errors in brackets).

\begin{tabular}{lllllcrr}
\hline Endophyte & Taxon & Host & Type & $\mathrm{n}$ & NFL & NAL & NANL \\
\hline Wild type & N. lolii & PRG & N & 4 & $0(0)$ & $0(0)$ & $0(0)$ \\
AR501 & FaTG-3 & TF & A & 5 & $129(16)$ & $0(0)$ & $0(0)$ \\
\hline
\end{tabular}

${ }^{1}$ Perennial ryegrass infected with wild type endophyte was cv. 'Supernui'; AR501 was present in an experimental perennial ryegrass line.

\section{DISCUSSION}

The presence or absence of loline alkaloids, and their concentrations within herbage, was highly dependent upon species, taxon or strain of endophyte. Most endophyte/grass combinations contained NFL and NAL, and some of these also contained NANL. In tall fescue and meadow fescue, it was possible to identify endophyte isolates inducing the production of high or low loline concentrations. However, in some associations, no lolines were detected. Lolines have not normally been found in grasses infected with $N$. lolii (Siegel et al. 1990) so it is not surprising that they were absent in meadow fescue infected with AR29 and perennial ryegrass infected with wild type $N$. lolii. The presence of NFL and NAL is associated with N. coenophialum infection of tall fescue, with NFL levels typically at least two to three times higher than NAL levels (Bush et al. 1982; Yates et al. 1990; TePaske et al. 1993). The results of the present study showed that not all Neotyphodium endophytes from tall fescue conformed to these criteria. NFL and NAL were absent in tall fescue infected with one strain of $N$. coenophialum (AR542), even though NANL was present. Lolines were also absent in plants infected with tall fescue endophytes (AR508, AR555 and AR583) belonging to other taxonomic groupings. In addition, an unusual NFL to NAL ratio of 1:1 was observed in tall fescue plants infected with several N. coenophialum strains (AR512, AR513, AR514, AR524 and AR525).

Plant species also played a role in determining patterns of loline alkaloid production. Concentrations of NFL, NAL and NANL were generally higher in meadow fescue than tall fescue. This difference can be clearly seen where the same endophyte isolates were present in different host grasses (AR501, AR506, and AR512). With the exception of NAL in AR512, the concentration of each of the loline alkaloids was higher in meadow fescue than tall fescue. In the case of AR512, it is interesting to note that in meadow fescue, the typically high ratio of NFL to NAL was found, while in tall fescue, the ratio was approximately $1: 1$. Thus, the ratio of NFL to NAL is influenced by plant species as well as endophyte isolate. Although only one loline-producing perennial ryegrass association was tested, loline concentrations appear lowest in this host, as the same endophyte strain (AR501) elicited higher levels in tall fescue and meadow fescue.

As well as quantitative effects, qualitative differences in loline alkaloid content due to plant species were observed. NANL was not detected in tall fescue and perennial ryegrass infected with AR501 and tall fescue infected with AR506, whereas NANL was present in meadow fescues infected with the same endophytes. Unlike tall fescue and meadow fescue, in which NFL and NAL were present, perennial ryegrass infected with AR501 did not contain NAL. Investigating the production of loline alkaloids in perennial ryegrass infected with $N$. coenophialum, Bush et al. (1993) detected both NFL and NAL, but found that the relative amount of NAL to NFL was reduced. NFL, but not NAL was observed in Festuca gigantea infected with a Neotyphodium sp., and Poa autumnalus infected with N. coenophialum (Bush et al. 1993). 
Little is known about the sensitivity of New Zealand insect pests to loline alkaloids. There is evidence that in tall fescue and meadow fescue, lolines may be responsible for endophyte-mediated resistance against grass grub (Costelytra zealandica), a serious pest of New Zealand pastures (Popay et al. 1993). Lolines are also active against several other insects, including cereal aphid (Rhopalosiphum padi), greenbug (Schizaphis graminum), large milkweed bug (Oncopeltusfasciatus), Japanese beetle (Popillia japonica) and corn flea beetle (Chaetocnema pulicaria) (Johnson et al. 1985; Yates et al. 1989; Siegel et al. 1990; Patterson et al. 1991; O. Ball unpubl. data), suggesting that this group of alkaloids may have a relatively broad spectrum of activity. More research on the insect resistance properties of the lolines is required in order to determine whether their presence should be an important criterion with respect to development of improved forages. If their presence is important, the findings of the current study could have major implications, as qualitative and quantitative aspects of loline production are likely to influence insect resistance properties.

\section{ACKNOWLEDGEMENTS}

We thank K. Fraser (AgResearch, Grasslands, Palmerston North) for assistance with the loline analysis, and G. Latch and M. Christensen (AgResearch, Grasslands, Palmerston North) for supplying seed.

\section{REFERENCES}

Bush, L.P., Cornelius, P.L., Buckner, R.C., Varney, D.R., Chapman, R.A., Burrus, P.B., Kennedy, C.W., Jones, T.A. and Saunders, M.J., 1982. Association of $N$ acetyl loline and $\mathrm{N}$-formyl loline with Epichloe typhina in tall fescue. Crop Sci. 22: 941-943.

Bush, L.P., Fannin, F.F, Siegel, M.R., Dahlman, D.L. and Burton, H.R., 1993. Chemistry, occurrence and biological effects of saturated pyrrolizidine alkaloids associated with endophyte-grass interactions. Agric. Ecosyst. Environ. 44: 81-102.

Christensen, M.J., Leuchtmann, A., Rowan, D.D. and Tapper, B.A., 1993. Taxonomy of Acremonium endophytes of tall fescue (Festuca arundinacea), meadow fescue (F. pratensis) and perennial ryegrass (Lolium perenne). Mycol. Res. 97: 10831092.

Dahlman, D.L., Eichenseer, H. and Siegel, M.R., 1991. Chemical perspectives on endophyte grass interactions and their implications to insect herbivory. Pp. 227252. In: Microbial Mediation of Plant-Herbivore Interactions, P. Barbosa, V.A. Krischik, and C.G. Jones (Eds). Wiley, New York.

Fletcher, L.R. and Easton, H.S., 1997. The evaluation and use of endophytes for pasture improvement. Pp 209-227. In: Proc. $3^{\text {rd }}$ Int. Symp. Neotyphodium/Grass Interactions, C.W. Bacon and N.S. Hill (Eds). Plenum Press.

Johnson, M.C., Dahlman, D.L., Siegel, M.R., Bush, L.P., Latch, G.C.M., Potter, D.A. and Varney, D.R., 1985. Insect feeding deterrents in endophyte-infected tall fescue. Appl. Environ. Microbiol. 49: 568-571.

Justus, M., Witte, L. and Hartmann, T., 1997. Levels and tissue distribution of loline alkaloids in endophyte-infected Festuca pratensis. Phytochem. 44: 51-57.

Latch, G.C.M. and Christensen, M.J., 1985. Artificial infection of grasses with endophytes. Ann. Appl. Biol. 107: 17-24.

Patterson, C.G., Potter, D.A. and Fannin, F.F., 1991. Feeding deterrency of alkaloids from endophyte-infected grasses to Japanese beetle grubs. Entomol. Exp. Appl. 61: 285-289.

Popay, A.J., Mainland, R.A. and Saunders, C.J., 1993. The effect of endophytes in fescue grass on growth and survival of third instar grass grub larvae. Pp. 174-176. In: Proc. $2^{\text {nd }}$ Int. Symp. on Acremonium/Grass interactions, D.E. Hume, G.C.M. Latch and H.S. Easton (Eds). AgResearch, Palmerston North, New Zealand.

Popay, A.J. and Rowan, D.D., 1994. Endophytic fungi as mediators of plant-insect interactions. Pp 83-103. In: Insect-Plant Interactions 5, E.A. Bernays (Ed). CRC Press. 
Siegel, M.R., Latch, G.C.M., Bush, L.P., Fannin, F.F., Rowan, D.D., Tapper, B.A., Bacon, C.W. and Johnson, M.C., 1990. Fungal endophyte-infected grasses: Alkaloid accumulation and aphid response. J. Chem. Ecol. 16: 3301-3315.

TePaske, M.R., Powell, R.G. and Clement, S.L., 1993. Analysis of selected endophyteinfected grasses for the presence of loline-type and ergot-type alkaloids. J. Agric. Food Chem. 41: 2299-2303.

Yates, S.G., Fenster, J.C. and Bartelt, R.J., 1989. Assay of tall fescue seed extracts, fractions, and alkaloids using the large milkweed bug. J. Agric. Food Chem. 37: 354-357.

Yates, S.G., Petroski, R.J. and Powell, R.G., 1990. Analysis of loline alkaloids in endophyte-infected tall fescue by capillary gas chromatography. J. Agric Food Chem. 38: 182-185. 